\title{
Acute Optogenetic Silencing of Orexin/Hypocretin Neurons Induces Slow-Wave Sleep in Mice
}

\author{
Tomomi Tsunematsu, ${ }^{1,2}$ Thomas S. Kilduff, ${ }^{3}$ Edward S. Boyden, ${ }^{4}$ Satoru Takahashi, ${ }^{5}$ Makoto Tominaga, ${ }^{1,2}$ \\ and Akihiro Yamanaka ${ }^{1,2,6}$ \\ ${ }^{1}$ Division of Cell Signaling, National Institute for Physiological Sciences, Okazaki 444-8787, Japan, ${ }^{2}$ Department of Physiological Sciences, The Graduate \\ University for Advanced Studies, Okazaki 444-8787, Japan, ${ }^{3}$ Biosciences Division, SRI International, Menlo Park, California 94025, ${ }^{4}$ Department of \\ Biological Engineering, Massachusetts Institute of Technology, Cambridge, Massachusetts 02139, ${ }^{5}$ Laboratory Animal Resource Center, University of

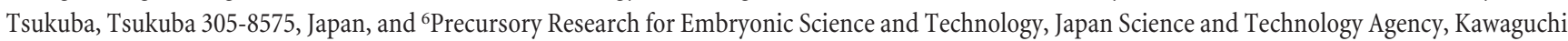 \\ 332-0012, Japan
}

Orexin/hypocretin neurons have a crucial role in the regulation of sleep and wakefulness. To help determine how these neurons promote wakefulness, we generated transgenic mice in which orexin neurons expressed halorhodopsin (orexin/Halo mice), an orange lightactivated neuronal silencer. Slice patch-clamp recordings of orexin neurons that expressed halorhodopsin demonstrated that orange light photic illumination immediately hyperpolarized membrane potential and inhibited orexin neuron discharge in proportion to illumination intensity. Acute silencing of orexin neurons in vivo during the day (the inactive period) induced synchronization of the electroencephalogram and a reduction in amplitude of the electromyogram that is characteristic of slow-wave sleep (SWS). In contrast, orexin neuron photoinhibition was ineffective during the night (active period). Acute photoinhibition of orexin neurons during the day in orexin/Halo mice also reduced discharge of neurons in an orexin terminal field, the dorsal raphe (DR) nucleus. However, serotonergic DR neurons exhibited normal discharge rates in mice lacking orexin neurons. Thus, although usually highly dependent on orexin neuronal activity, serotonergic DR neuronal activity can be regulated appropriately in the chronic absence of orexin input. Together, these results demonstrate that acute inhibition of orexin neurons results in time-of-day-dependent induction of SWS and in reduced firing rate of neurons in an efferent projection site thought to be involved in arousal state regulation. The results presented here advance our understanding of the role of orexin neurons in the regulation of sleep/wakefulness and may be relevant to the mechanisms that underlie symptom progression in narcolepsy.

\section{Introduction}

Orexins/hypocretins are neuropeptides expressed in a specific population of neurons in the lateral hypothalamic area (LHA) (de Lecea et al., 1998; Sakurai et al., 1998). Animals that lack these peptides, orexin neurons, or functional orexin-2 receptors show phenotypes similar to that of the sleep disorder narcolepsy (Chemelli et al., 1999; Lin et al., 1999; Hara et al., 2001; Willie et al., 2003), that is, sleep/ wakefulness fragmentation and cataplexy. The onset of human narcolepsy usually occurs after adolescence. The most common initial symptom is excessive daytime sleepiness (EDS), followed by cataplexy and hallucinations (Okun et al., 2002; Morrish et al., 2004;

Received Feb. 14, 2011; revised April 29, 2011; accepted May 21, 2011.

Author contributions: T.T., T.S.K., and A.Y. designed research; T.T. and A.Y. performed research; T.T., E.S.B., S.T., and A.Y. contributed unpublished reagents/analytic tools; T.T., T.S.K., and A.Y. analyzed data; T.T., T.S.K., E.S.B., M.T., and A.Y. wrote the paper.

This study was supported by the Japan Science and Technology Agency Precursory Research for Embryonic Science and Technology program, Grant-in-Aid for Young Scientist (A), Scientific Research on Priority Areas (Integrative Brain Research) from the Ministry of Education, Culture, Sports, Science, and Technology of Japan (A.Y.), a Japan Society for Promotion of Science postdoctoral fellowship (T.T.), and NIH Grant R01NS057464 (T.S.K.). We thank C. Saito and K. Nishimura for technical assistance and Dr. Jaime Heiss for useful comments on this manuscript.

Correspondence should be addressed to Dr. Akihiro Yamanaka, Division of Cell Signaling, National Institute for Physiological Sciences, National Institute of Natural Sciences, Okazaki 444-8787. E-mail: yamank@nips.ac.jp.

DOI:10.1523/JNEUROSCI.0784-11.2011

Copyright $\odot 2011$ the authors $\quad 0270-6474 / 11 / 3110529-11 \$ 15.00 / 0$
Ohayon et al., 2005). The pathophysiology of narcolepsy is related to orexin deficiency (Peyron et al., 2000; Thannickal et al., 2000). Indeed, central administration of orexin induces wakefulness and decreases slow-wave sleep (SWS) and rapid eye movement (REM) sleep durations (Hagan et al., 1999; Piper et al., 2000). Orexin neurons fire phasically during active wakefulness (AW) and are silent during SWS (Lee et al., 2005; Mileykovskiy et al., 2005). These findings indicate that the orexin system has a critical role in the regulation of sleep/wakefulness, especially in the maintenance of arousal.

Orexin neurons densely innervate the monoaminergic nuclei that are implicated in the regulation of sleep/wakefulness, including the dorsal raphe nucleus (DR), locus ceruleus (LC), and tuberomammillary nucleus (TMN) (Peyron et al., 1998; Sakurai et al., 1998; Horvath et al., 1999; Nambu et al., 1999; Bayer et al., 2001; Yamanaka et al., 2002; Sakurai, 2007). Orexin innervates and activates DR neurons (Brown et al., 2001, 2002), and, conversely, orexin neurons are innervated by serotonergic neurons and inhibited by serotonin (Muraki et al., 2004; Sakurai et al., 2005). Although this reciprocal neural circuit has been proposed to stabilize the distribution of sleep/wakefulness in a coordinated manner, how orexin neuronal activity influences sleep/wakefulness is incompletely understood.

To address this issue, we have created a transgenic mouse in which the orange light-activated neuronal silencer halorhodopsin 
(Halo) (Han and Boyden, 2007; Zhang et al., 2007), is expressed in orexin neurons, and we acutely inactivated these neurons in vitro and in vivo. Optogenetics using the light-activated neuronal activator channelrhodopsin-2 has been used previously to explore orexin neuron function (Adamantidis et al., 2007; Carter et al., 2009). We find that illumination of orexin neurons expressing Halo resulted in inhibition of orexin neurons in vitro. Acute silencing of orexin neurons in vivo induced changes in the electroencephalogram (EEG) and electromyogram (EMG) that are characteristic of SWS. Furthermore, during silencing of orexin neurons in vivo, serotonergic DR neuron activity decreased to levels observed during SWS, indicating a loss of excitatory drive associated with inactivation of orexin neurons. However, in orexin/ataxin-3 mice, the activity of DR neurons was indistinguishable from that of wild-type mice, suggesting that compensatory regulation occurs in the chronic absence of orexin input.

\section{Materials and Methods}

Animal usage. All experimental procedures involving animals were approved by the National Institute for Physiological Sciences Animal Care and Use Committee and were in accordance with NIH guidelines. All efforts were made to minimize animal suffering or discomfort and to reduce the number of animals used.

Generation of orexin/Halo transgenic mice. The transgenic construct was made by substituting the $n L a c Z$ gene (SalI-BamHI fragment) of the orexin $/ n L a c Z$ transgenic construct (Sakurai et al., 1999) with the $1.6 \mathrm{~kb}$ Halo fragment (Han and Boyden, 2007), which is expressed as a fusion protein with enhanced green fluorescent protein (EGFP). The transgene was excised and microinjected into pronuclei of fertilized mouse eggs (BDF1 mice) to generate transgenic founders. Founders were bred with BDF1 mice to produce stable orexin/Halo transgenic lines. A total of 13 transgene-positive founders were obtained in the orexin/Halo transgenic mice. Analysis of the $\mathrm{N} 1$ generation demonstrated that only three lines (lines 5, 7, and 8) showed a sufficiently strong expression of Halo. Among these lines, line 5 was used for subsequent experiments because this line showed the highest expression rate ( $94 \%$ of orexin neurons).

Brain slice preparation. Male and female orexin/EGFP (Yamanaka et al., 2003a,b) and orexin/Halo transgenic mice (3-4 weeks old) were used for whole-cell recordings. The mice were deeply anesthetized with isoflurane (Abbott Japan) and decapitated. Brains were quickly isolated in ice-cold cutting solution consisting of the following: $280 \mathrm{~mm}$ sucrose, 2 mM KCl, $10 \mathrm{~mm} \mathrm{HEPES}, 0.5 \mathrm{~mm} \mathrm{CaCl} 2,10 \mathrm{~mm} \mathrm{MgCl}_{2}$, and $10 \mathrm{~mm}$ glucose, pH 7.4 with $\mathrm{NaOH}$, bubbled with $100 \% \mathrm{O}_{2}$. Brains were cut coronally into $350 \mu \mathrm{m}$ slices with a microtome (VTA-1200S; Leica). Slices containing the LHA were transferred to an incubation chamber filled with physiological solution containing the following: $135 \mathrm{~mm} \mathrm{NaCl}, 5 \mathrm{~mm}$ $\mathrm{KCl}, 1 \mathrm{~mm} \mathrm{CaCl}_{2}, 1 \mathrm{~mm} \mathrm{MgCl}_{2}, 10 \mathrm{~mm}$ HEPES, and $10 \mathrm{~mm}$ glucose, $\mathrm{pH}$ 7.4 with $\mathrm{NaOH}$, bubbled with $100 \% \mathrm{O}_{2}$ and incubated for at least $1 \mathrm{~h}$ at room temperature (RT) $\left(24-26^{\circ} \mathrm{C}\right)$.

In vitro electrophysiological recordings. At RT, the slices were transferred to a recording chamber (RC-27L; Warner Instruments) on a fluorescence microscope stage (BX51WI; Olympus). Neurons that had EGFP fluorescence were identified as orexin neurons and were subjected to electrophysiological recordings. The fluorescence microscope was equipped with an infrared camera (C2741-79; Hamamatsu Photonics) for infrared differential interference contrast imaging and a cooled charge-coupled device (CCD) camera (Cascade 650; Roper Scientific) for fluorescent imaging. Each image was displayed separately on a monitor and saved on a computer. Recordings were performed with an Axopatch 200B amplifier (Molecular Devices) using a borosilicate pipette (GC15010; Harvard Apparatus) prepared by a micropipette puller (P-97; Sutter Instruments), filled with intracellular solution (4-6 M $\Omega$ ) consisting of the following (in mM): $138 \mathrm{~K}$-gluconate, $10 \mathrm{HEPES}, 8 \mathrm{NaCl}, 0.2 \mathrm{EGTA}-$ $\mathrm{Na}_{3}, 2 \mathrm{MgATP}$, and $0.5 \mathrm{Na}_{2} \mathrm{GTP}$, pH 7.3 with $\mathrm{KOH}$. The osmolarity of the solution was checked by a vapor pressure osmometer (model 5520; Wescor). The osmolarity of the internal and external solutions was $280-$ 290 and 320-330 mOsm/L, respectively. The liquid junction potential of the patch pipette and perfused extracellular solution was estimated to be $16 \mathrm{mV}$ and was corrected in the data. Recording pipettes were under positive pressure while advancing toward individual cells in the slice, and tight seals on the order of $1.0-1.5 \mathrm{G} \Omega$ were made by negative pressure. The membrane patch was then ruptured by suction. The series resistance during recording was $10-25 \mathrm{M} \Omega$. The reference electrode was an $\mathrm{Ag}-$ $\mathrm{AgCl}$ pellet immersed in bath solution. During recordings at RT, cells were superfused with extracellular solution at a rate of $1.6 \mathrm{ml} / \mathrm{min}$ using a peristaltic pump (Dynamax; Rainin).

Orange or blue light was generated by a xenon lamp $(75 \mathrm{~W}$, model UXL-75XB; Olympus) by passing through an FF01-586/20-25 filter (586 $\pm 10 \mathrm{~nm}$; Semrock) or FF01-472/30-25 filter (472 $\pm 15 \mathrm{~nm}$; Semrock), respectively, controlled by a filter changer (Lambda 10-2; Sutter Instruments) via MetaFluor 5.0.7 software (Universal Imaging). To alter light intensity, neutral density filters ( 6 and $25 \%$ permeation) on the fluorescent microscope were used.

The output signal was low-pass filtered at $5 \mathrm{kHz}$ and digitized at 10 $\mathrm{kHz}$. Data were recorded on a computer through a Digidata 1322A analog-to-digital converter using pClamp software version 10.2 (Molecular Devices).

Drugs. Tetrodotoxin (TTX) (Wako) was dissolved in extracellular solution at a concentration of $1 \mu \mathrm{M}$. During the experiments, TTX was applied by bath application.

Immunohistochemical studies. Male and female orexin/Halo transgenic mice (4 or 15 weeks old) were deeply anesthetized with isoflurane and perfused sequentially with $20 \mathrm{ml}$ of chilled saline and $20 \mathrm{ml}$ of chilled $10 \%$ Formalin solution (Wako). The brains were removed and immersed in the above fixative solution for $24 \mathrm{~h}$ at $4^{\circ} \mathrm{C}$ and then immersed in a $30 \%$ sucrose solution for at least $2 \mathrm{~d}$. The brains were quickly frozen in embedding solution (Sakura Finetechnical). For orexin and GFP double staining, coronal sections $(40 \mu \mathrm{m})$ of orexin/Halo transgenic mouse brains were incubated with rabbit anti-GFP antiserum (1:1000; Invitrogen) for $24 \mathrm{~h}$ at $4^{\circ} \mathrm{C}$. These sections were incubated with Alexa Fluor 488-labeled anti-rabbit IgG (1:800; Invitrogen) for $1 \mathrm{~h}$ at RT. The sections were then incubated with guinea pig anti-orexin antiserum (1:500) for $24 \mathrm{~h}$ at $4^{\circ} \mathrm{C}$ and incubated with Alexa Fluor 594-labeled goat antiguinea pig IgG (1:800; Invitrogen) for $1 \mathrm{~h}$ at RT. The sections were mounted and examined with a fluorescence microscope (BZ-9000; Keyence) or a confocal microscope (LSM510; Carl Zeiss).

To confirm the position of implanted fiber optics, cryostat coronal sections $(50 \mu \mathrm{m})$ were stained by the avidin-biotin-peroxidase method. Briefly, brain sections were incubated for $40 \mathrm{~min}$ in Tris-buffered saline containing $0.3 \% \mathrm{H}_{2} \mathrm{O}_{2}$ to inactivate endogenous peroxidase. Sections were transferred into Tris-buffered saline containing $0.25 \%$ Triton $\mathrm{X}-100$ and $1 \%$ bovine serum albumin fraction V (TBS-BX) for $30 \mathrm{~min}$ and then incubated with guinea pig anti-orexin antibody diluted 1:800 in TBS-BX overnight at $4^{\circ} \mathrm{C}$. Sections were then incubated with biotinlabeled anti-guinea pig IgG goat antibody (Vector Laboratories) diluted 1:1000 in TBS-BX for $1 \mathrm{~h}$ at RT, followed by incubation with avidin and biotinylated peroxidase complex solution for $30 \mathrm{~min}$ at RT. Bound peroxidase was visualized by incubating sections with 3,3-diaminobenzidine tetrahydrochloride (ImmPACT DAB peroxidase substrate; Vector Laboratories), resulting in a golden-brown reaction product. The sections were mounted and examined with a microscope (BZ-9000; Keyence). To confirm the specificity of antibodies, incubations without primary antibody were conducted as a negative control in each experiment, and no signal was observed. To determine whether neuronal death occurred in the lateral hypothalamic area subjected to photic illumination, tissue sections containing this region were immunostained for the microglial marker IbaI. For IbaI staining, brain sections were incubated with rabbit anti-IbaI antiserum (Wako) for $24 \mathrm{~h}$ at $4^{\circ} \mathrm{C}$. These sections were incubated with biotin-labeled anti-rabbit IgG goat antibody (Vector Laboratories) diluted 1:1000 in TBS-BX for $1 \mathrm{~h}$ at RT, followed by incubation with avidin and biotinylated peroxidase complex solution for $30 \mathrm{~min}$ at RT. Bound peroxidase was visualized by incubating sections with 3,3-diaminobenzidine tetrahydrochloride in the presence of $0.25 \%$ nickel ammonium sulfate (ImmPACT DAB peroxidase substrate; Vector Laboratories), resulting in a black reaction product. 
In vivo extracellular recordings. Fifteen-week-old male orexin/Halo mice, their wild-type littermates and orexin/ataxin-3 transgenic mice [N13 backcrossed to C57BL/6J; kindly supplied by Dr. Sakurai, Kanazawa University, Kanazawa, Japan (Hara et al., 2001)] were housed under controlled lighting ( $12 \mathrm{~h} \mathrm{light/dark} \mathrm{cycle;} \mathrm{lights} \mathrm{on} \mathrm{from} \mathrm{8:00} \mathrm{A.M.}$ to 8:00 P.M. ) and temperature $\left(22^{\circ} \mathrm{C}\right)$ conditions. Food and water were available ad libitum. Mice were anesthetized with isoflurane using a vaporizer for small animals (SF-B01; DS Pharma Biomedical) and positioned in a stereotaxic frame (David Kopf Instruments). Plastic fiber optics (0.5 mm diameter; Eska; Mitsubishi Rayon) were bilaterally implanted $\sim 1 \mathrm{~mm}$ above the LHA (1.7 $\mathrm{mm}$ posterior, $1 \mathrm{~mm}$ lateral from bregma, $4 \mathrm{~mm}$ depth). Electrodes for EEG and EMG were implanted on the skull and neck muscle, respectively. A U-shaped plastic plate was attached to the skull using dental cement (GC Corporation) to enable fixation of the mouse's head to the stereotaxic frame during extracellular recordings. The mice were then housed separately for a recovery period of at least $7 \mathrm{~d}$.

After the $7 \mathrm{~d}$ recovery period, the skull ( $4.5 \mathrm{~mm}$ posterior from bregma) was drilled under isoflurane (1\%) anesthesia (SF-B01; DS Pharma Biomedical) to make a window to allow subsequent insertion of a glass recording microelectrode. The window was covered by an antibiotic-containing ointment (tetracycline, $30 \mathrm{mg} / \mathrm{g}$; Pfizer) to protect from drying and infection until the day of experiment. After another $2 \mathrm{~d}$ recovery period, mice were placed in a plastic box fitted to their body and then attached to the stereotaxic frame via the U-shaped plastic plate with water provided ad libitum. Acclimation to the stereotaxic instrument occurred for $2 \mathrm{~d}$ at the same time of day (11:00 A.M. to 7:00 P.M.) during which the experiments were scheduled. By the second acclimation day, all mice showed spontaneous sleep while in the stereotaxic frame. On the day of the experiment, mice were mounted in the stereotaxic frame at 11:00 A.M. with water provided ad libitum and recordings were performed between 1:00 P.M. and 7:00 P.M.

The activity of single neurons was recorded extracellularly using a glass pipette microelectrode (WPI) filled with a $0.5 \mathrm{M}$ sodium acetate solution containing $2 \%$ Pontamine Sky Blue (PSB) (15-30 M $\Omega$ ). The difference in electrical potential was amplified (Intra 767; WPI), filtered, and digitized at a sampling rate of $10 \mathrm{kHz}$ (Micro1401; Cambridge Electronic Design). A window discriminator (model 121 discriminator; WPI) was used to isolate a specific unit from noise or the activity of other neurons. Serotonergic neurons were discriminated from others using the following criteria: (1) a longer duration of the action potential; (2) a shoulder on the falling phase or a deflection in the negative component of action potentials; and (3) the firing pattern during sleep/wakefulness (tonic firing during wakefulness, decreased firing frequency during SWS, and quiescence during REM sleep) (Takahashi et al., 2005). EEG and EMG signals were amplified (DAM70; WPI), filtered, digitized at a sampling rate of $200 \mathrm{~Hz}$ (EEG) and $100 \mathrm{~Hz}$ (EMG), and recorded using Spike 2 software (version 5.04; Cambridge Electronic Design).

To mark the tip of the recording electrode by PSB labeling, current was injected through the recording electrode ( $10 \mu \mathrm{A}$ for $6 \mathrm{~min})$. After the experiment, the mice were decapitated and perfused sequentially with 20 $\mathrm{ml}$ of chilled saline and $20 \mathrm{ml}$ of chilled $10 \%$ Formalin solution (Wako). The brains were removed and immersed in the same fixative solution for $24 \mathrm{~h}$ at $4^{\circ} \mathrm{C}$. The brains were quickly frozen in embedding solution (Sakura Finetechnical). For counterstaining, coronal sections $(50 \mu \mathrm{m})$ of the brains of wild-type, orexin/Halo transgenic, or orexin/ataxin-3 transgenic mice were incubated with the reduced form of $\beta$-nicotinamideadenine dinucleotide phosphate ( $\beta$-NADPH) (Oriental Yeast Co.) and nitroblue tetrazolium (Wako) for $30 \mathrm{~min}$ at $37^{\circ} \mathrm{C}$ and then stained with neutral red (Sigma).

In vivo photo illumination using freely moving mice. Continuous EEG and EMG recordings were performed through a slip ring (Air Precision) designed so that the movement of the mouse was unrestricted. EEG and EMG signals were amplified (AB-610J; Nihon Koden), filtered (EEG, $1.5-30 \mathrm{~Hz}$; EMG, 15-300 Hz), digitized at a sampling rate of $128 \mathrm{~Hz}$, and recorded using SleepSign software version 3 (Kissei Comtec). Orange light was generated by LED ( $590 \pm 5 \mathrm{~nm}, 1 \mathrm{~W}$; OSY5XME1C1E; OptoSupply) and applied through plastic optical fibers bilaterally inserted 1 $\mathrm{mm}$ above the LHA. An optical swivel (COME2; Lucir) was used for unrestricted in vivo photo illumination. Orange light power intensity at the tip of the plastic fiber optics $\left(0.5 \mathrm{~mm}\right.$ diameter) was $0.4 \mathrm{~mW} / \mathrm{mm}^{2}$ measured by power meter (VEGA; Ophir Optronics). Preliminary studies indicated that the physiological response to photic illumination subsided with illumination durations longer than $1 \mathrm{~min}$ and could not be replicated within the same recording session, suggesting photolysis or internalization of the halorhodopsin protein. Accordingly, orange light illumination was performed for 1 min durations between 1:00 P.M. and 7:00 P.M. (light period) and 9:00 P.M. and 11:00 P.M. (dark period). Each mouse received photic illumination from one to three times with an interval of at least $4 \mathrm{~d}$ between each illumination. The animal's behavior was monitored through a CCD video camera and recorded on a computer synchronized with EEG and EMG recordings using the SleepSign video option system (Kissei Comtec).

Behavioral state classification and EEG power spectral analyses. EEG/ EMG records were automatically scored in $4 \mathrm{~s}$ epochs and classified as wakefulness, SWS, or REM sleep by SleepSign software according to standard criteria (Tobler et al., 1997; Yamanaka et al., 2002). All vigilance state classifications assigned by SleepSign were examined visually and corrected if necessary. The same individual, blinded to genotype and experimental condition, scored all EEG/EMG recordings. Spectral analysis of the EEG was performed by fast Fourier transform (FFT) (sampled at $128 \mathrm{~Hz}$ ). This analysis yielded a power spectra profile over a $0-40 \mathrm{~Hz}$ window with a $1 \mathrm{~Hz}$ resolution divided into delta $(1-5 \mathrm{~Hz})$, theta $(6-10$ $\mathrm{Hz})$, alpha $(10-13 \mathrm{~Hz})$, and beta $(13-25 \mathrm{~Hz})$ waves. An average EEG spectrum profile was calculated from EEG power densities in each frequency bin and then expressed as average power values of delta, theta, alpha, and beta waves for each state.

Statistical analysis. Data were analyzed by unpaired $t$ test, paired $t$ test, and one-way or two-way ANOVA, as appropriate for the parameters examined, using the KaleidaGraph 4.0 software (Hulinks). When appropriate, ANOVA tests were followed by post hoc analysis of significance using Fisher's protected least significant difference test. $p$ values $<0.05$ were considered statistically significant.

\section{Results}

\section{Specific expression of halorhodopsin in orexin neurons}

We generated transgenic mice in which orexin neurons specifically expressed Halo under control of the human prepro-orexin promoter (orexin/Halo transgenic mice). This $3.2 \mathrm{~kb}$ DNA fragment allows the expression of exogenous genes in the orexin neurons (Sakurai et al., 1999, 2005; Hara et al., 2001; Moriguchi et al., 2002; Yamanaka et al., 2003b; Tsujino et al., 2005). The specific expression of Halo by orexin neurons was confirmed by double-labeled immunohistochemistry. An anti-GFP antibody was used to detect Halo because Halo is expressed as a fusion protein with GFP. A merged picture (GFP-IR and orexin-IR) revealed that Halo was exclusively observed in orexin neurons (Fig. 1). No expression of Halo was observed throughout the brain other than in orexin neurons. GFP-IR was observed in the soma and dendrites (Fig. $1 B$, arrows) of orexin neurons but not in the axons (Fig. $1 B$, arrowhead). Orexin neurons expressing Halo did not show blebbing or other features indicative of inappropriate trafficking (Fig. $1 \mathrm{~B}$ ). In the orexin/Halo transgenic mice, 3 of 13 transgenic mouse lines (lines 5, 7, and 8) expressed Halo in orexin neurons. Halo expression rate (GFP-IR/orexinIR $\times 100 \%)$ of lines 5,7 , and 8 was $94.1 \pm 0.7 \%(n=3), 31.7 \pm$ $2.3 \%(n=3)$, and $85.9 \pm 3.6 \%(n=3)$, respectively. Because line 5 showed the highest expression, these mice were used for all subsequent in vivo and in vitro experiments. The number and morphology of orexin-IR neurons in the line 5 orexin/Halo transgenic mice were indistinguishable from those of wild-type mice (data not shown). 
Membrane properties of Halo-expressing orexin neurons

To confirm the function of Halo expressed in the transgenic mouse brain, slice patchclamp analyses were performed. First, we tested whether the basic membrane properties of orexin neurons were affected by the expression of Halo. Electrical properties of Halo-expressing orexin neurons were compared with those of EGFP-expressing orexin neurons in orexin/EGFP transgenic mice. There were no significant differences in the resting membrane potential, peak amplitude of action potential, spontaneous firing, input resistance, or membrane capacitance between these strains (Table 1). Along with the apparent normal morphology of orexin/ halo neurons (Fig. $1 \mathrm{~B}$ ), these results indicate that the anatomy and physiology of orexin neurons were not adversely affected by Halo expression in these cells.

\section{Orange light illumination \\ hyperpolarizes Halo-expressing orexin neurons}

Orexin neurons were whole-cell patch clamped and orange light (wavelength, $586 \pm 10 \mathrm{~nm}$ ) was illuminated through an objective lens. Orange light illumination immediately hyperpolarized the membrane potential and completely inhibited the generation of spontaneous action potentials in orexin neurons (Fig. 2A). In contrast, neither blue (wavelength $472 \pm$ $15 \mathrm{~nm}$ ) nor orange light had an effect on the membrane potential of orexin neurons in orexin/EGFP transgenic mice; this suggests that orange light-induced hyperpolarization was caused by the activation of Halo (Fig. $2 \mathrm{~B}$ ). Non-orexin neurons, which did not have GFP fluorescence, showed no response to orange or blue light illumination in either orexin/EGFP or orexin/Halo mice (data not shown). In the presence of TTX, orange light illumination also induced hyperpolarization, suggesting a direct effect (Fig. 2C). The magnitude of Halo-mediated hyperpolarization depended on the light intensity (Fig. 2C). Orange light-induced hyperpolarizations of orexin neurons were $1.8 \pm 0.2 \mathrm{mV}[n=5$, $p=0.40$, not significantly different (NS), $5.5 \pm 1.3 \mathrm{mV}(n=5$, $p=0.0061), 7.5 \pm 1.5 \mathrm{mV}(n=5, p<0.001)$, and $11.3 \pm 2.4 \mathrm{mV}$ $(n=5, p<0.001)$ under light intensities of $1.5,6,25$, and $100 \%$ (4 mW), respectively (Fig. 2D). Blue light illumination (100\% intensity) had little effect on the membrane potential of Haloexpressing orexin neurons $(2.3 \pm 0.9 \mathrm{mV}, n=5, p=0.27$, NS). Conversely, neither blue (100\% intensity) nor orange (100\% intensity) light affected the membrane potential of orexin neurons in orexin/EGFP transgenic mice. The higher sensitivity of Halo to orange light than to blue light is corroborated by previous reports (Han and Boyden, 2007; Zhang et al., 2007). Thus, subsequent slice patch-clamp experiments used the $100 \%$ light intensity level. Hyperpolarization was also induced by short $(2 \mathrm{~s})$ repetitive and longer (10 s) illumination durations (Fig. 2E,F). The hyperpolarization levels induced by repetitive $2 \mathrm{~s}$ pulses of orange light were $6.5 \pm 0.9 \mathrm{mV}$ (first application, $n=7, p<0.001$ ), $6.9 \pm 0.9$ $\mathrm{mV}$ (second application, $n=7, p<0.001$ ), $7.8 \pm 1.0 \mathrm{mV}$ (third
Table 1. Electrical membrane properties of Halo-expressing orexin neurons

\begin{tabular}{lrr}
\hline & Halo $(+)$ orexin neurons & \multicolumn{1}{c}{ EGFP $(+)$ orexin neurons } \\
\hline Resting membrane potential $(\mathrm{mV})$ & $-52.8 \pm 2.1(n=5)$ & $-52.5 \pm 1.7(n=6)$ \\
Peak amplitude $(\mathrm{mV})$ & $17.3 \pm 1.6(n=6)$ & $13.4 \pm 3.0(n=5)$ \\
Spontaneous firing $(\mathrm{Hz})$ & $4.8 \pm 1.0(n=5)$ & $4.7 \pm 1.0(n=8)$ \\
Input resistance $(\mathrm{M} \Omega)$ & $531.2 \pm 76.7(n=7)$ & $489.3 \pm 30.2(n=12)$ \\
Membrane capacitance $(\mathrm{pF})$ & $27.1 \pm 1.5(n=9)$ & $27.2 \pm 2.0(n=11)$ \\
\hline
\end{tabular}

Values are means \pm SEM.

application, $n=7, p<0.001$ ), $6.2 \pm 0.9 \mathrm{mV}$ (fourth application, $n=7, p<0.001$ ), and $4.8 \pm 0.8 \mathrm{mV}$ (fifth application, $n=7, p=$ 0.0015 ) (Fig. $2 G$ ). Although hyperpolarization gradually decreased with repetitive orange light illumination, it was still significant in response to the fifth pulse.

Next, we tested the ability of Halo to enable sustained, rapidly inducible and reversible inhibition of orexin neuronal activity. Under current-clamp mode, a rectangular depolarizing current $(0.5 \mathrm{~Hz}, 4-15 \mathrm{pA}, 250 \mathrm{~ms})$ was injected through the recording electrode to generate artificial action potentials. Orange light illumination for $10 \mathrm{~s}$ completely inhibited current injectioninduced action potentials (Fig. $2 H$ ). The probability of current injection-induced firing was normalized to the $10 \mathrm{~s}$ before light illumination. Firing probability during orange light illumination was significantly reduced to $6.7 \pm 4.6 \%(n=6, p<0.001)$ of control levels (Fig. 2I). Firing completely recovered after termination of orange light illumination $(93.3 \pm 4.6 \%$ of control, $n=$ 


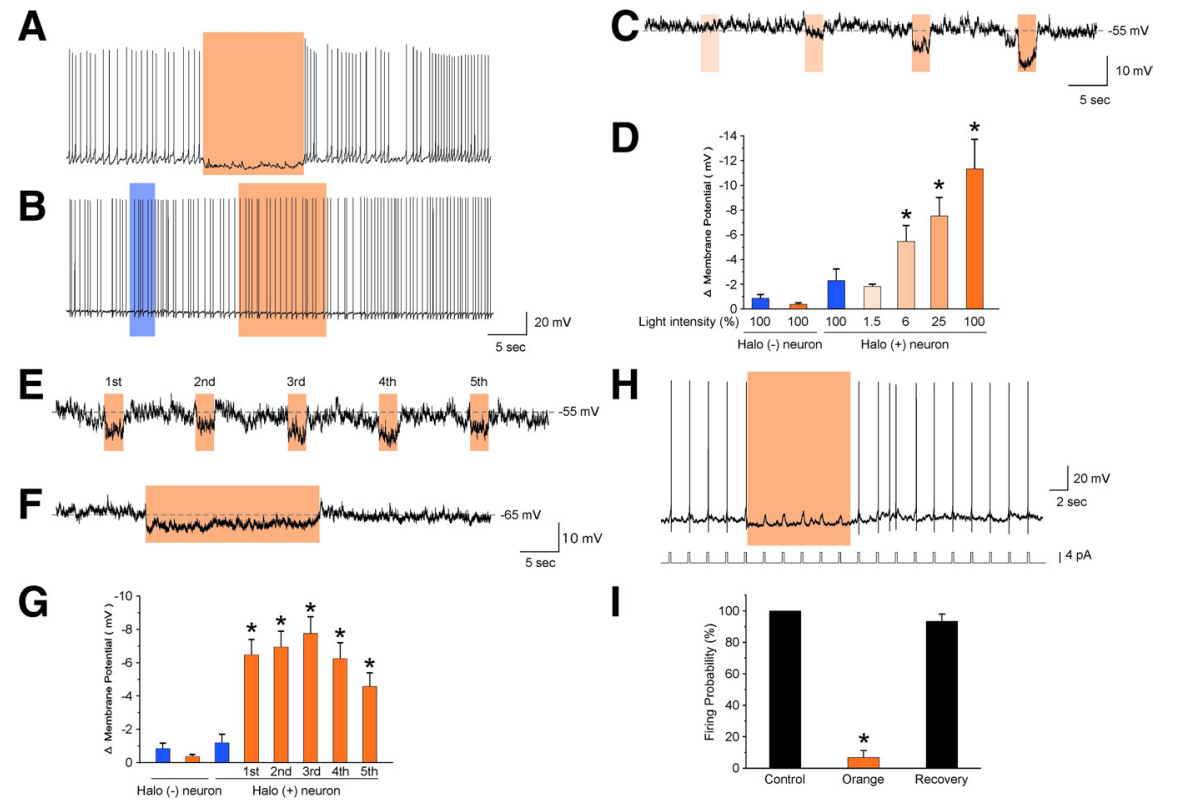

Figure 2. Orange light inhibits the activity of Halo-expressing orexin neurons. $\boldsymbol{A}$, Under whole-cell current-clamp mode, orange light illumination induced instantaneous hyperpolarization and completely inhibited spontaneous action potentials in Haloexpressing orexin neurons. $\boldsymbol{B}$, Neither blue nor orange light illumination had an effect on membrane potential or spontaneous firing frequency in orexin neurons expressing EGFP alone in orexin/EGFP mice. C, Orange light induced hyperpolarization in a light intensity-dependent manner in the presence of TTX. Light intensities are 1.5, 6, 25, and 100\% (from left to right). D, Bar graph summarizing the data in $C(n=5)$. Halo $(+)$ neuron, Halo-expressing orexin neurons from orexin/Halo mice; Halo $(-)$ neuron, EGFP-expressing orexin neurons from orexin/EGFP mice. $\boldsymbol{E}, \boldsymbol{F}$, Brief $(2 \mathrm{~s})$, repetitive illumination $(\boldsymbol{E})$ and longer (20 s), continuous illumination $(\boldsymbol{F})$ induced hyperpolarization in the presence of TTX. G, Bar graph summarizing the data in $\boldsymbol{E}(n=7)$. $\boldsymbol{H}$, Orange light also inhibited current injection-induced action potentials. Orange light illumination for 10 s inhibited firing elicited by rectangular current pulse injection through the recording electrode $(0.5 \mathrm{~Hz}, 4 \mathrm{pA}, 250 \mathrm{~ms})$. I, The bar graph shows the firing probability calculated from the data in $\boldsymbol{H}(n=6)$. Firing probability is normalized to $10 \mathrm{~s}$ before light illumination. Orange light was applied through the objective lens, as represented by the colored bar. Values are represented as means \pm SEM. ${ }^{*} p<0.05$ vs orange light illumination of Halo ( - ) orexin neurons.

$6, p=0.19, \mathrm{NS})$. These results indicate that the activity of Haloexpressing orexin neurons can be continuously and repeatedly inhibited by orange light illumination.

\section{Orange light illumination induces an outward current in Halo-expressing orexin neurons}

Under voltage-clamp mode, a significant outward current was induced by repetitive, brief ( $2 \mathrm{~s}$ ) or longer (10 s) orange light illumination durations in Halo-expressing orexin neurons in the presence of TTX (Fig. $3 A, B)$. Holding membrane potential $\left(V_{\mathrm{m}}\right)$ at $-60 \mathrm{mV}$, the orange light-induced outward current was $5.7 \pm$ $0.4 \mathrm{pA}(n=8, p<0.001)$ (Fig. $3 C)$. The current was not affected by changing the holding potential from -60 to -40 or $-90 \mathrm{mV}$, consistent with the belief that Halo is a chloride ion pump. The reversal potential of chloride under the recording conditions used was calculated as $-74 \mathrm{mV}$. Holding $V_{\mathrm{m}}$ at -40 or $-90 \mathrm{mV}$, the orange light-induced current was $5.8 \pm 0.3 \mathrm{pA}(n=6, p<$ $0.001)$ or $5.4 \pm 0.5 \mathrm{pA}(n=6, p<0.001)$, respectively (Fig. $3 C)$. In contrast, blue light had little effect on current in Haloexpressing orexin neurons, which was in agreement with the current-clamp results ( $1.6 \pm 0.2 \mathrm{pA}, n=5, p=0.06$, NS).

\section{Orange light inhibits spontaneous firing in orexin neurons}

Orange light-induced inhibition of orexin neurons was confirmed using loose cell-attached recording, which monitors firing frequency without affecting the intracellular conditions of the neuron being recorded in the brain slice preparation. Before light stimulation, orexin neurons had a spontaneous firing rate of $3.2 \pm 0.3 \mathrm{~Hz}$ $(n=6)$. Repetitive 2 s orange light illumination completely inhibited spontaneous firing in Halo-expressing orexin neurons (Fig. $4 A$ ). The firing probability during repetitive orange light illumination significantly decreased to $9.0 \pm 4.8 \%$ (first response, $n=6$, $p<0.001$ ), $10.4 \pm 7.4 \%$ (second response, $n=6, p<0.001$ ), and $18.8 \pm 13.1 \%$ (third response, $n=6, p<0.001$ ) of control levels (Fig. $4 B$ ). Next, to determine the duration of Halo-induced silencing, orange light was continuously illuminated for $3 \mathrm{~min}$. Loose cell-attached recording revealed that orange light illumination immediately inhibited spontaneous firing. Although spontaneous firing gradually recovered after 1 min illumination, inhibition was still significant even after 3 min illumination (57.9 $\pm 5.6 \%$, $n=7, p=0.00018$, paired $t$ test vs basal firing) (Fig. $4 C, D$ ). When illumination was terminated, firing greatly increased but returned to basal levels within $2 \mathrm{~min}$. These results strongly suggested that orange light illumination of the hypothalamus would inhibit the activity of orexin neurons in vivo. Based on these results, the following in vivo experiments were performed.

\section{In vivo orange light illumination of the hypothalamus induces SWS in mice during the light, but not dark, period} To study the physiological significance of orexin neuronal activity in the regulation of sleep/wakefulness, we performed in vivo photic illumination of the hypothalamus using freely moving orexin/Halo transgenic mice. To determine the sleep/wakefulness state during recording, mice were chronically implanted with EEG and EMG electrodes. To deliver orange light to the hypothalamus, plastic fiber optics were bilaterally implanted into the brain. During the time when mice showed spontaneous wakefulness in the late light period (1:00 P.M. to 7:00 P.M.), orange light was illuminated for $60 \mathrm{~s}$ through the fiber optics from an LED light source $(590 \pm 5 \mathrm{~nm})$. During orange light illumination of the hypothalamus, EEG power gradually increased and EMG power gradually decreased (Fig. $5 A$ ). Spectral analysis of the EEG was performed by FFT on $4 \mathrm{~s}$ recording epochs. Cortical EEG power spectra revealed that spectral intensities, particularly that of the delta range, increased in conjunction with orange light illumination, suggesting the induction of SWS (Fig. 5B-F, Table 2). During the second half of the $60 \mathrm{~s}$ photic illumination period, all orexin/Halo transgenic mice showed SWS $(n=7)$ (Fig. $5 G-I)$. After termination of photic illumination, the EEG showed fast waves and increased EMG levels were observed, indicating that the mice were awake (Fig. $5 A$ ). Interestingly, after a brief period of wakefulness, mice tended to fall asleep again without any additional photic illumination (Fig. $5 A, G$ ).

In contrast to the results described above, orange light illumination of the hypothalamus of awake, freely moving orexin/Halo transgenic mice had no effect on the sleep/wakefulness pattern during the dark period (9:00 P.M. to 11:00 P.M.) when nocturnal mice have the greatest spontaneous activity and arousal level $(n=$ 10) (Fig. $5 J-L$ ). In a limited number of experiments during the 


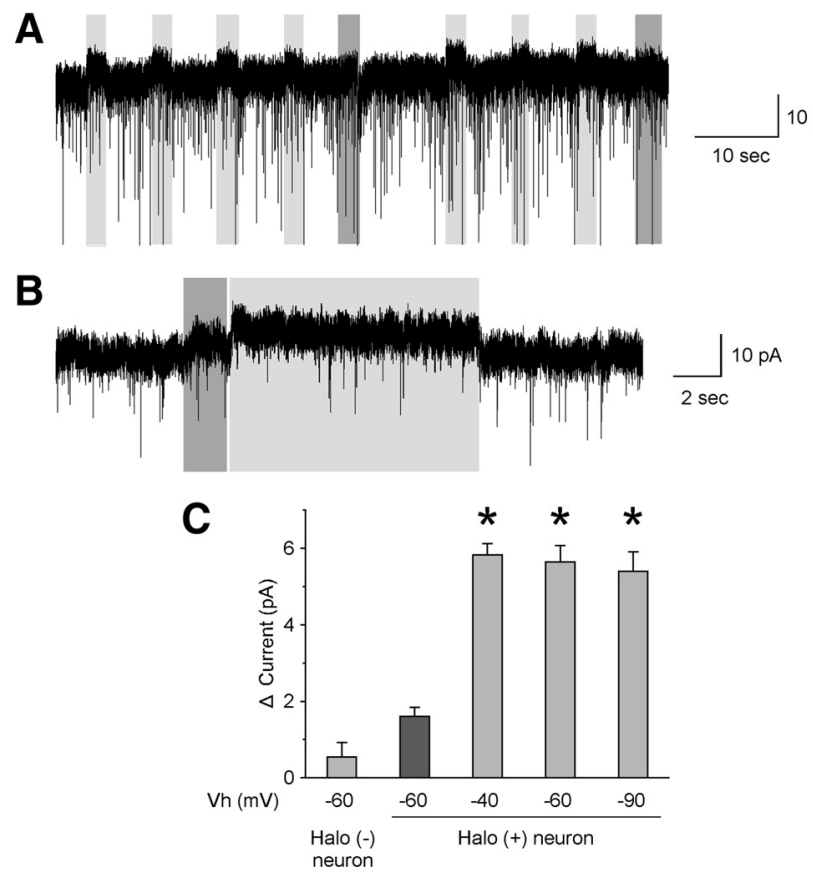

Figure 3. Orange light illumination induces an outward current in Halo-expressing orexin neurons. $A$, Under voltage-clamp mode, with membrane potential held at $-60 \mathrm{mV}$, brief $(2 \mathrm{~s})$, repetitive orange light illumination induced an outward current in the presence of TTX. In contrast, blue light illumination had little effect. $\boldsymbol{B}$, Longer (10 s) illumination induced a continuous outward current in the presence of TTX with membrane potential held at $-60 \mathrm{mV}$. C, Bar graph summarizing blue or orange light-induced outward current under holding potentials of $-40,-60$, or $-90 \mathrm{mV}(n=5-8)$. Halo $(+)$, Halo-expressing orexin neurons from orexin/ Halo mice; Halo (-), EGFP-expressing orexin neurons from orexin/EGFP mice. Blue or orange light was applied through an objective lens as indicated by gray bars. Blue or orange light application is dark gray or light gray, respectively. Values are represented as means \pm SEM. ${ }^{*} p<0.05$ vs Halo $(-)$ neurons. $V_{h}$, Holding potential.

dark period, orange light illumination occurred while mice were in SWS, but neither wakefulness nor REM sleep resulted. Silencing of orexin neurons at either time of day did not induce an acute transition from wakefulness to REM sleep as occurs in narcoleptic patients and mice.

After the experiments, immunohistochemical analyses confirmed that the tip of the fiber optics was $\sim 1 \mathrm{~mm}$ above the orexin neuron field in the LHA $(n=10)$ (Fig. 6). Brains were also stained using an anti-IbaI antibody, a marker of microglial cells that are activated after brain injury and that remove dead neurons by phagocytosis. Although activation of microglia was observed near the fiber scars, no signs of activation of microglia cells were observed in the illuminated area (i.e., the lateral hypothalamic area). These results suggest that orange light illumination did not induce injury in brain (data not shown).

\section{Photic inhibition of orexin neurons reduces firing of neurons in an orexin terminal field}

To further study the physiological significance of orexin neuronal activity in sleep/wakefulness regulation in conjunction with other arousal-promoting nuclei, EEG/EMG and the activity of DR neurons were simultaneously recorded using in vivo extracellular recording (Fig. 7A). Serotonergic neurons in the DR are densely innervated by orexin neurons and are directly and indirectly activated by orexin (Brown et al., 2001). orexin/Halo transgenic mice were mounted in the stereotaxic frame via a plastic U-shaped frame fixed onto the skull. During extracellular recording, the mouse was conscious and showed spontaneous bouts of
A
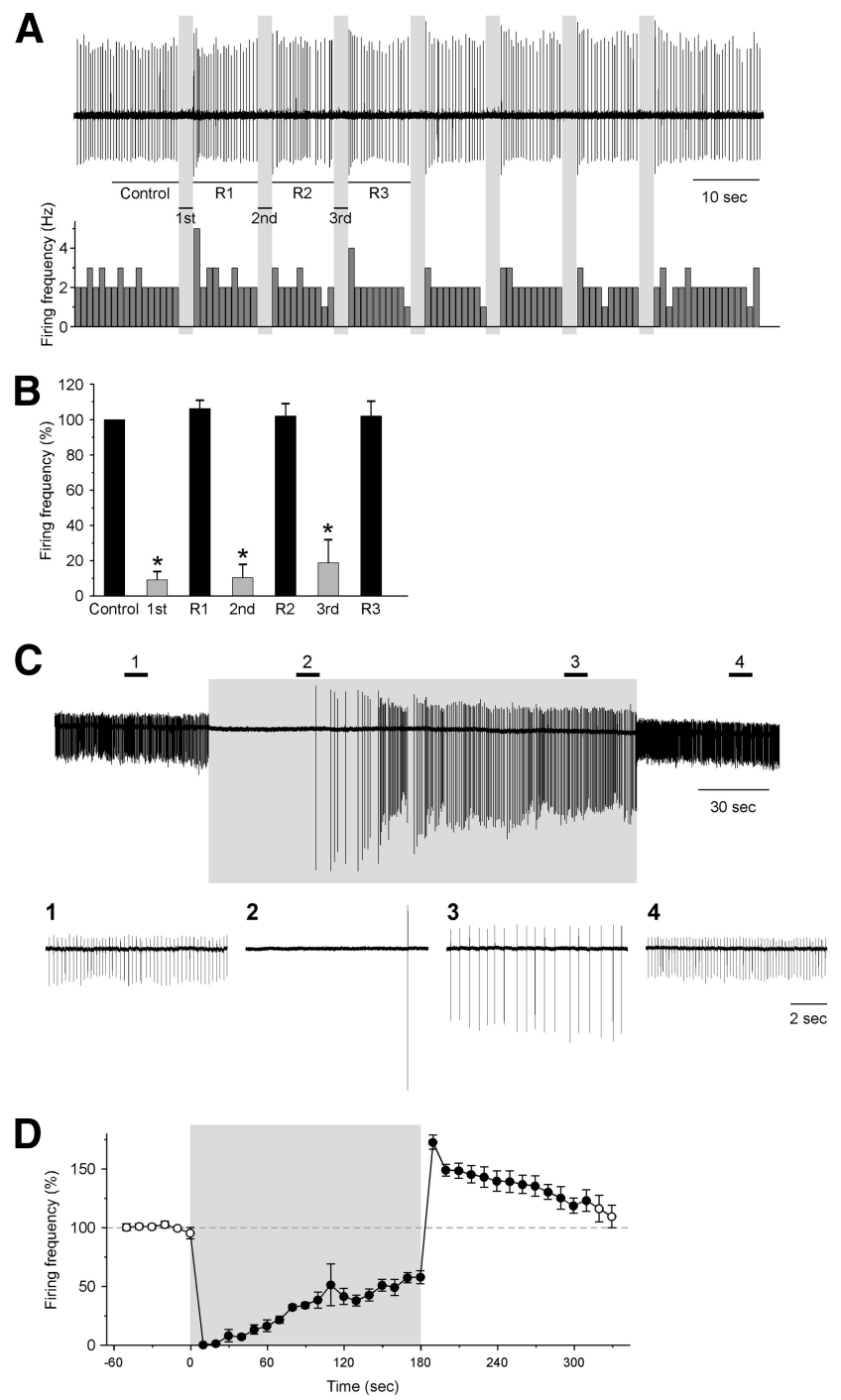

Figure 4. Orange light illumination blocks spontaneous firing of orexin neurons. $\boldsymbol{A}$, In a loose cell-attached recording from Halo-expressing orexin neurons in vitro, brief $(2 \mathrm{~s})$ pulses of orange light illumination completely inhibited spontaneous firing. Top, Spontaneous action potentials; bottom, histogram of firing frequency plotted in $1 \mathrm{~s}$ bins. $\boldsymbol{B}$, Bar graph summarizing the firing probability of orexin neurons during control conditions and during 2 s periods of orange illumination $(n=6)$. The firing probability was normalized to the spontaneous firing frequency during the 10 s before illumination. R1, Recovery period between first and second response. R2, Recovery period between second and third response. R3, Recovery period after third response. C, In a loose cell-attached recording from Halo-expressing orexin neurons in vitro, continuous illumination for $3 \mathrm{~min}$ also inhibited spontaneous firing. Regions indicated by bar and number were magnified in the bottom. $\boldsymbol{D}$, Line graph summarizing data in $\boldsymbol{C}(n=7)$. Basal frequency for 60 s before experiment was set as 100\%. Orange light was applied through an objective lens as indicated by the gray bar. Values are means \pm SEM. ${ }^{*}$ or filled circle, $p<0.05$ versus control.

sleep and wakefulness (see Materials and Methods). First, the spontaneous sleep/wakefulness pattern in orexin/Halo transgenic mice was analyzed to determine whether the presence of the Halo transgene affected normal sleep/wakefulness regulation under the restraint condition. Thus, we compared the sleep/wakefulness episode durations and cortical EEG power spectra in orexin/ Halo transgenic mice with those of wild-type littermate mice. Neither the episode durations nor the EEG power spectra during the late light period (1:00 P.M. to 7:00 P.M.) differed significantly between the two genotypes (Fig. 7C, Table 3). The average EEG power densities in delta $(1-5 \mathrm{~Hz})$, theta $(6-10 \mathrm{~Hz})$, alpha $(10-13$ $\mathrm{Hz}$ ), and beta (13-25 Hz) bandwidths within each sleep/wakeful- 
A

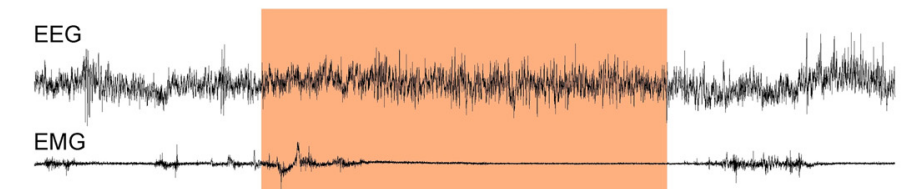

B

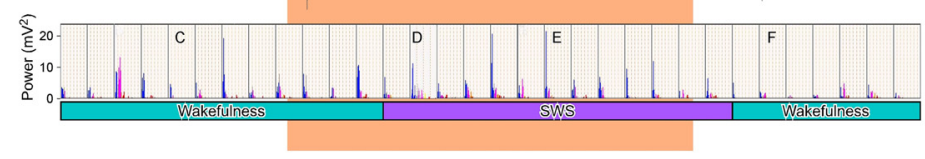

C
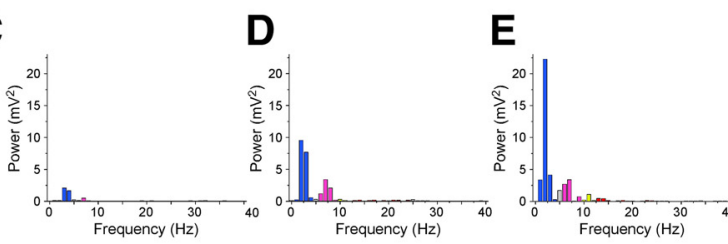

$\mathbf{F}$

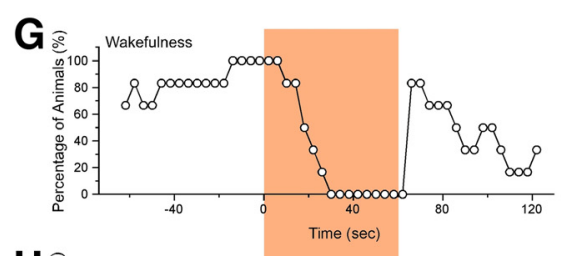

J ฮ

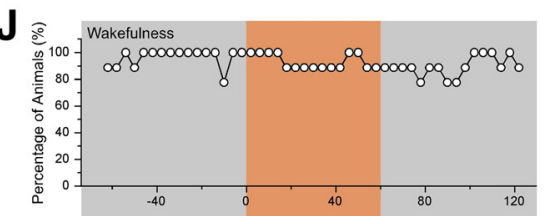

$\mathbf{H}$
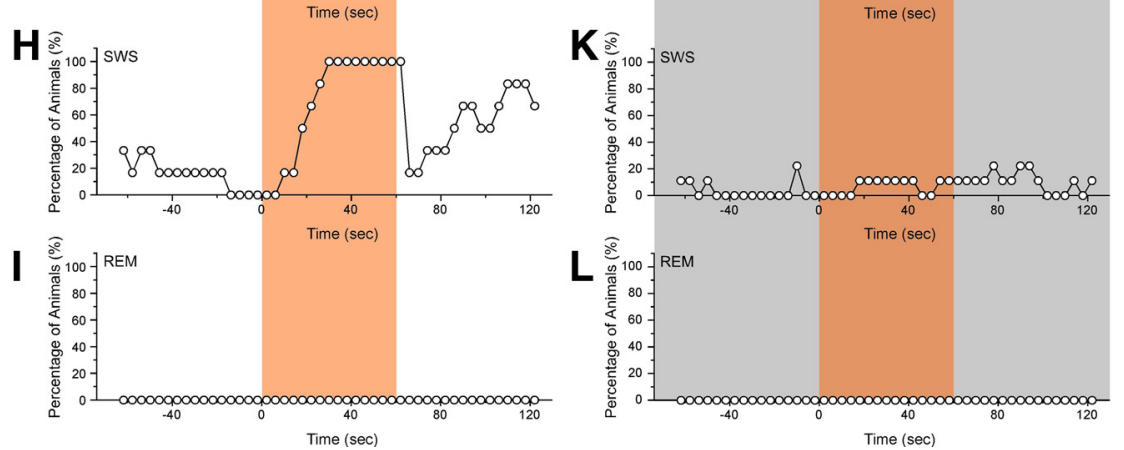

Figure 5. Acute inhibition of orexin neurons induces SWS. EEG and EMG electrodes were chronically implanted to determine sleep/wakefulness state. Plastic fiber optics ( $0.5 \mathrm{~mm}$ diameter) were bilaterally inserted into the hypothalamus. Orange light from an LED $(590 \pm 5 \mathrm{~nm})$ was applied through the fiber optics. $A$, Representative traces show EEG (top trace) and EMG (bottom trace) during orange light illumination during the second half of the light period (1:00 P.M. to 7:00 P.M.). Orange light illumination was initiated at a random time when orexin/Halo mice were awake. $\boldsymbol{B}$, Bar graph shows EEG power spectra of each epoch $(4 \mathrm{~s})$ corresponding to $A$. Bar graph shows a typical EEG power spectrum before illumination $(\boldsymbol{C})$, during illumination $(\boldsymbol{D}, \boldsymbol{E})$, and after cessation of illumination $(\boldsymbol{F})$. Line graphs summarize the percentage of animals showing wakefulness $(\boldsymbol{G}, \boldsymbol{J})$, SWS $(\boldsymbol{H}, \boldsymbol{K})$, and REM sleep $(I, L)$ during orange light illumination in the light period (1:00 P.M. to 7:00 P.M.; $n=7 ; \boldsymbol{G}-I)$ and in the dark period (9:00 P.M. to 11:00 P.M.; $n=10 ; \boldsymbol{J}-\boldsymbol{L}$ ). The data in $\mathbf{G}-\boldsymbol{L}$ are based on experiments in which mice had been awake at least for $8 \mathrm{~s}$ ( 2 epochs) during either the light or dark period before orange light illumination. The orange shading indicates the period of light illumination. A total of seven mice were tested for in vivo photic illuminations. These mice were used for photic illumination during both the light and dark periods.

ness state were not significantly different between the two groups either $(n=13)$ (Fig. 7C).

The firing frequency of DR neurons was then compared between wild-type littermates and orexin/Halo transgenic mice during wakefulness, SWS, and REM sleep. DR neurons that were likely to be serotonergic were identified according to previously reported electrophysiological criteria (Takahashi et al., 2005) - a longer duration action potential, a shoulder on the falling phase, and/or a deflection in the negative component of action potentials (Fig. 7B) - and will be referred to here as "presumably serotonergic." We found that the firing frequency of presumably serotonergic DR neurons was not significantly different between wild-type littermates and orexin/Halo transgenic mice in any sleep/wakefulness stage (Fig. 7D). The firing frequencies of DR neurons during wakefulness, SWS, and REM sleep in wild-type mice were $2.9 \pm 0.5 \mathrm{~Hz}(n=13), 1.2 \pm 0.2 \mathrm{~Hz}(n=22)$, and $0.03 \pm 0.02 \mathrm{~Hz}(n=9)$, respectively, and those in orexin/Halo transgenic mice were $3.3 \pm 0.5 \mathrm{~Hz}(n=$ $12, p=0.38, \mathrm{NS}), 1.4 \pm 0.2 \mathrm{~Hz}(n=26$, $p=0.53, \mathrm{NS})$, and $0.01 \pm 0.01 \mathrm{~Hz}(n=6$, $p=0.97, \mathrm{NS}$ ), respectively (Fig. $7 D$ ). The position of the recording electrode was confirmed after each experiment by marking the tip of the electrode using PSB labeling (Fig. 7E). These results indicate that neither the EEG spectral power properties nor the activity of presumably serotonergic DR neurons were affected by expression of Halo in orexin neurons.

Next, we studied the effect of acute orange light inhibition of orexin neurons on sleep/wakefulness and presumably serotonergic DR neuron activity. During times when mice showed spontaneous wakefulness in the late light period (1:00 P.M. to 7:00 P.M.), the LHA was illuminated with orange light for $60 \mathrm{~s}$ duration through the fiber optics using an LED light source $(590 \pm 5 \mathrm{~nm})$. During orange light illumination, EEG delta power gradually increased and EMG power gradually decreased (Fig. 7G, I, K). In addition, simultaneous in vivo extracellular recordings from presumably serotonergic DR neurons revealed that the firing frequency gradually decreased in conjunction with the EEG delta power increase. Furthermore, DR neuron discharge was markedly reduced during the second $30 \mathrm{~s}$ of illumination (Fig. $7 \mathrm{G}, J$ ). Immediately after the termination of orange light, firing in the DR neurons quickly recovered to the basal wakefulness level, and the EEG showed low amplitude, fast activity, and greater EMG levels indicative of wakefulness (Fig. 7G,J). These results are consistent with those observed in freely moving orexin/Halo transgenic mice subjected to photic illumination (Fig. $5 D, E$ ). In wild-type littermate mice, orange light illumination of the hypothalamus had little effect on the EEG, EMG, or the activity of DR neurons (Fig. $7 F$ ). The EEG power spectral analysis by FFT showed that EEG power in delta, theta, alpha, and beta bands was significantly increased during the second half of orange light illumination compared with the $30 \mathrm{~s}$ before illumination (Fig. 7I), although it did not reach the same amplitude characteristic of deep SWS that occurs 1-2 min after SWS onset (Fig. $7 H$ ). Simultaneous in vivo extracellular recording from presumably serotonergic $\mathrm{DR}$ neurons also showed that the firing rate was significantly reduced (Fig. 7J). The firing rates of DR neurons before illumination (pre), the first half illumination $(0-30 \mathrm{~s})$, the second half illumination (30-60 s), and after illumination (post) were $3.3 \pm 0.3 \mathrm{~Hz}(n=12), 2.1 \pm 0.2 \mathrm{~Hz}(n=12, p=0.0041), 0.9 \pm$ $0.3 \mathrm{~Hz}(n=12, p<0.001)$, and $3.2 \pm 0.3 \mathrm{~Hz}(n=12, p=0.84, \mathrm{NS})$, respectively. These results suggest that acute silencing of orexin neuronal activity by illuminating orange light into the hypothalamus decreased firing frequency of presumably serotonergic neurons in the DR and induced SWS in mice.

To further study the effect of orexin neuronal activity on the DR neurons, orexin/ataxin-3 transgenic mice, in which orexin 
Table 2. The average EEG power densities in the delta, theta, alpha, and beta wave bands

\begin{tabular}{lllll}
\hline & Pre & Orange (0-30 s) & Orange (30-60 s) & \multicolumn{1}{c}{ Post } \\
\hline Delta (\%) & 100 & $167.4 \pm 49.9$ & $165.9 \pm 59.3$ & $134.1 \pm 21.8$ \\
Theta (\%) & 100 & $113.1 \pm 22.4$ & $113.9 \pm 22.4$ & $68.9 \pm 10.3$ \\
Alpha (\%) & 100 & $164.0 \pm 29.0$ & $193.3 \pm 50.0$ & $106.2 \pm 22.6$ \\
Beta (\%) & 100 & $130.9 \pm 22.0$ & $149.1 \pm 39.1$ & $85.1 \pm 10.4$ \\
Total (\%) & 100 & $122.7 \pm 12.7$ & $176.6 \pm 21.3$ & $119.3 \pm 6.9$ \\
\hline
\end{tabular}

The average EEG power densities were normalized to the EEG during the $30 \mathrm{~s}$ before illumination $(n=7)$. Pre, $30 \mathrm{~s}$ before illumination; Post, $30 \mathrm{~s}$ after illumination; $0-30 \mathrm{~s}$, the first half 30 s illumination; $30-60 \mathrm{~s}$, the second half 30 s illumination. Values are represented as means \pm SEM.

A

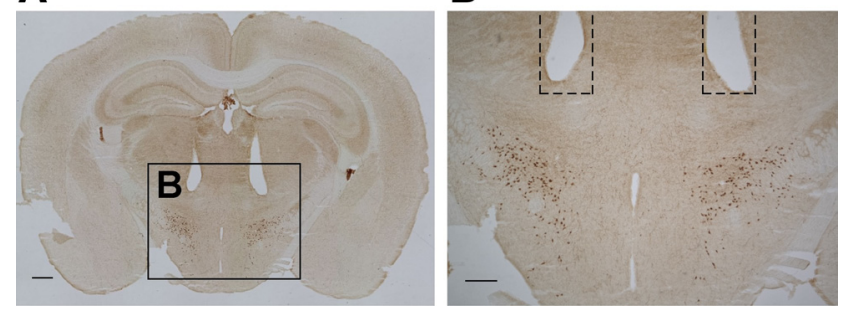

Figure 6. The location of the plastic fiber optic tip was confirmed after each experiment. Fiber optics were bilaterally implanted in the brain $1 \mathrm{~mm}$ above the LHA region in which orexin-IR neurons are located. $\boldsymbol{A}$, Orexin-IR neurons (brown) show scattered distribution in the LHA (brown). Scale bar, $500 \mu \mathrm{m}$. $\boldsymbol{B}$, Higher magnification of the square region indicated in $\boldsymbol{A}$. Scale bar, $300 \mu \mathrm{m}$. Dashed line indicates the position of implanted fiber optics $(0.5 \mathrm{~mm}$ in diameter).

neurons are specifically ablated (Hara et al., 2001), were subjected to extracellular recording. Orexin neurons are gradually eliminated in the brains of these transgenic mice, and almost all orexin neurons are gone by 10 weeks of age. The average EEG power densities in delta, theta, alpha, and beta bandwidths in each sleep/ wakefulness state did not significantly differ between wild-type mice and orexin/ataxin-3 transgenic mice (Fig. 7C). Surprisingly, no significant differences were observed in the firing frequency of DR neurons of orexin/ataxin-3 transgenic mice compared with wild-type mice in any vigilance state (wakefulness, SWS, or REM sleep). The firing frequencies of serotonergic neurons in orexin/ ataxin-3 transgenic mice during wakefulness, SWS, and REM sleep were $3.1 \pm 0.4 \mathrm{~Hz}(n=13, p=0.58$, NS), $1.4 \pm 0.2 \mathrm{~Hz}(n=$ $17, p=0.56, \mathrm{NS})$, and $0.004 \pm 0.004 \mathrm{~Hz}(n=12, p=0.96$, NS $)$, respectively $($ Fig. $7 D)$. These results suggest that presumably serotonergic DR neuronal activity is usually highly dependent on orexin neuronal activity but can apparently be normally regulated in the chronic absence of orexin input.

\section{Discussion}

Here, we described the first transgenic mice in which a lightsensitive protein is chronically expressed in orexin neurons. Acute optogenetic inhibition of orexin neurons with the orange light-activated neuronal silencer Halo induced SWS during the day, consistent with physiological importance for orexin neuronal activity in the maintenance of arousal. Although optogenetic activation of orexin neurons has been reported previously to increase wakefulness and reduce SWS and REM sleep (Adamantidis et al., 2007; Carter et al., 2009), the results obtained here were unexpected for several reasons. First, orexin neurons are only phasically active during AW, with periods of silence during both quiet wakefulness (QW) and AW (Lee et al., 2005; Mileykovskiy et al., 2005; Takahashi et al., 2008). Thus, there is no a priori reason to expect that acute inhibition of these cells during the second half of the inactive period (when QW predominates) would result in sleep. In fact, we expected that optogenetic inactivation would be most effective in sleep induction during the dark period, when AW predominates and orexin neuron firing would be greatest. In support of this prediction, orexin antagonists have been shown to induce sleep when administered during the dark period (Brisbare-Roch et al., 2007). Second, the concept of the orexin system as a wake-promoting system arose from the observation that orexin neurons degenerate in human narcoleptics, who have difficulty maintaining wakefulness. However, acute optogenetic inhibition is completely different from narcolepsy, in which chronic absence of orexin likely results in reorganization of the downstream circuitry controlling sleep/wakefulness.

\section{Specific expression of Halo enables silencing of orexin neuronal activity}

Neuronal expression of Halo in nematodes, zebrafish, and mice enables suppression of neural activity by orange light illumination (Han and Boyden, 2007; Zhang et al., 2007; Arrenberg et al., 2009). Here, Halo was expressed in almost all orexin neurons with no ectopic expression. The specific expression of Halo in orexin neurons affected neither the morphology of these cells, their membrane properties, nor the spectral characteristics of sleep/wakefulness states. Neurons from transgenic mice in which Halo is expressed under the Thyl promoter were electrophysiologically indistinguishable from other neurons (Zhao et al., 2008), demonstrating the safety and utility of Halo in mediating neural silencing. Although Halo and other molecules are commonly used in viral form in optogenetic studies, we demonstrated here that Halo transgenic mice can be used to study behavior in a scientifically and clinically relevant context. Whole-cell recordings demonstrated that orange light illumination induced hyperpolarization and completely inhibited spontaneous action potentials in Halo-expressing orexin neurons. In addition, orange light-induced silencing of orexin neuronal activity was observed using loose cell-attached recording, suggesting that orange light illumination could inhibit the activity of orexin neurons in vivo.

\section{Acute silencing of orexin neurons induced SWS but only during the day}

The firing rate of orexin neurons is greatest during AW; these cells are silent during sleep (Lee et al., 2005; Mileykovskiy et al., 2005). Mice lacking prepro-orexin, the OX2R gene, or orexin neurons exhibit reduced daily amounts of wakefulness (Chemelli et al., 1999; Hara et al., 2001; Willie et al., 2003), suggesting that the orexin system has a crucial role in the maintenance of wakefulness. However, how the activity of orexin neurons contributes to wakefulness control is incompletely understood. Consequently, the activity of orexin neurons was manipulated in vivo by optogenetics. Orange light illumination into the hypothalamus through implanted fiber optics induced a gradual EMG decrease and increased EEG delta power, indicating that acute silencing of orexin neurons in the late light period induced SWS in orexin/ Halo transgenic mice.

The EEG power spectrum in orange light-induced SWS did not reach the amplitude characteristic of deep SWS that occurs 1-2 min after SWS onset. Halo-induced SWS may still be a transitional state, perhaps because orexin neuron inhibition did not last $>1$ or 2 min, likely as a result of desensitization of the Halo protein. Alternatively, orange light-induced SWS may not be identical to physiological SWS because only one arousal system (the orexin system) is being inhibited directly. 
A

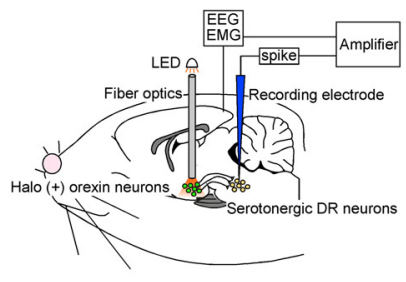

B

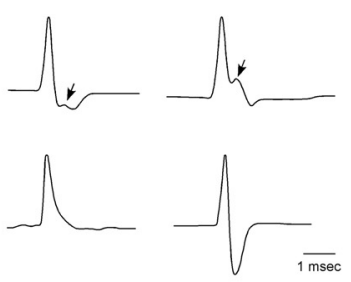

C
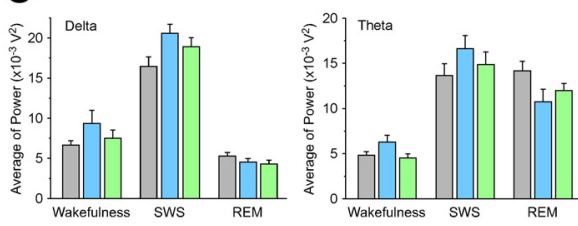

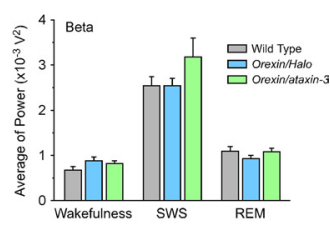

D

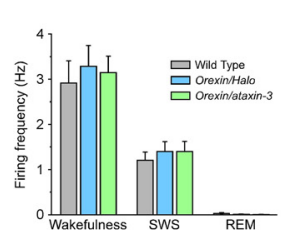

E

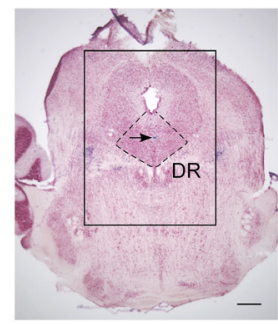

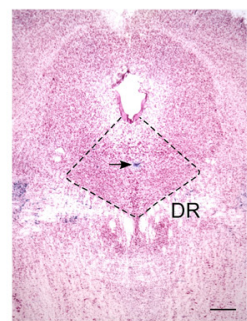

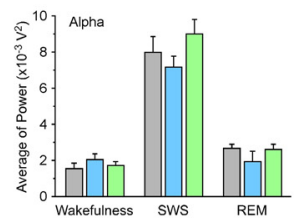

G

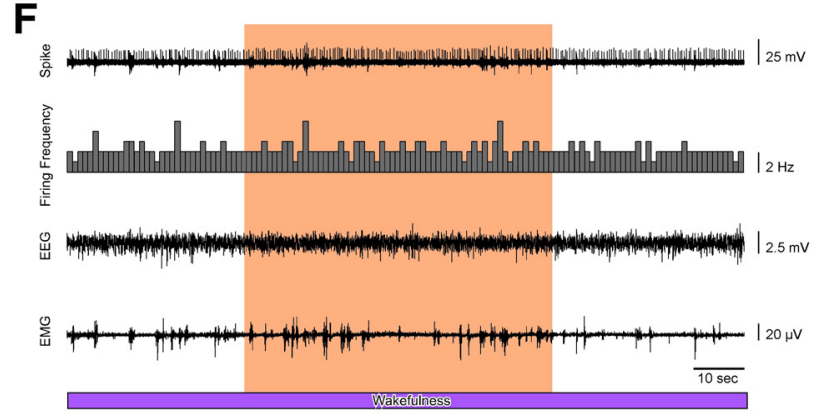

H

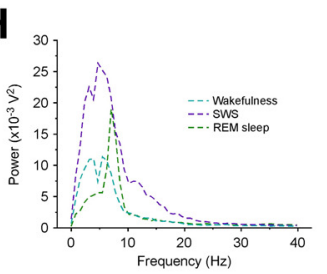

I
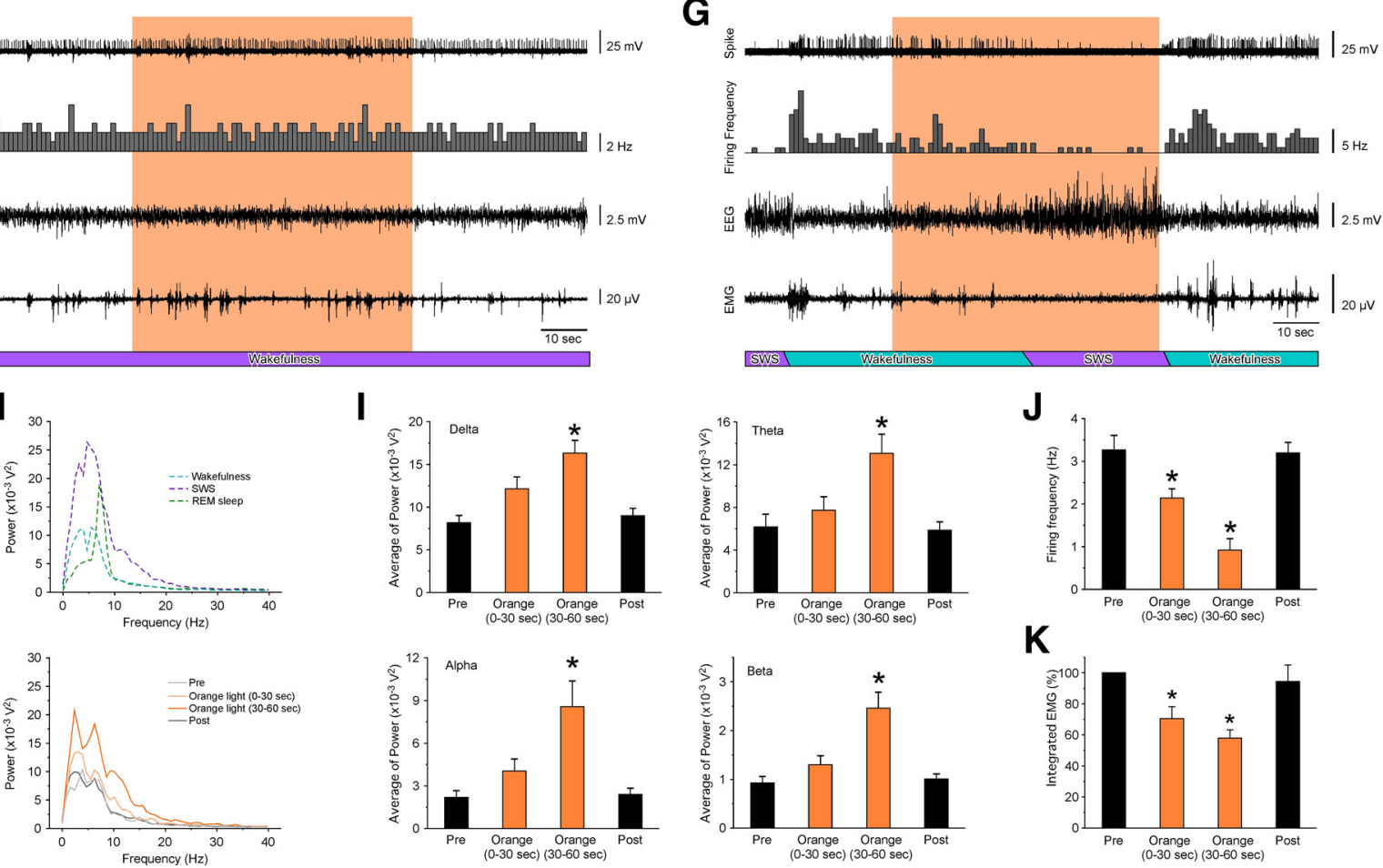

K
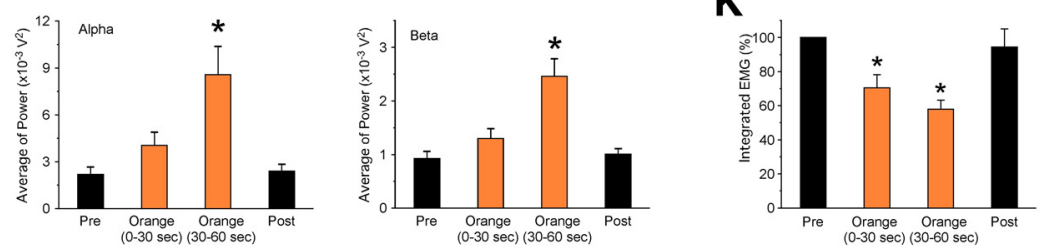

Figure 7. Acute inhibition of orexin neurons induces SWS and decreases the activity of serotonergic DR neurons. A, Schematic drawing of in vivo extracellular recordings from the DR and photic illumination of the hypothalamus using fiber optics. EEG and EMG electrodes were implanted to determine sleep/wakefulness state. Plastic fiber optics ( $0.5 \mathrm{~mm}$ diameter) were bilaterally inserted into the hypothalamus. Orange light from LED (590 $\pm 5 \mathrm{~nm}$ ) was applied through these fibers. Firing frequency of serotonergic DR neurons was recorded through a glass electrode inserted into the DR. $\boldsymbol{B}$, Averaged shape of spikes classified as presumably serotonergic neurons (top traces) and nonserotonergic neurons (bottom traces) in the DR. Serotonergic DR neurons have longer action potential duration ( $\sim 1 \mathrm{~ms}$ ) as well as a deflection in the negative component (arrow, top left trace) or a shoulder on the falling phase (arrow, top right trace). $C$, Bar graph summarizing the average EEG power density in the delta, theta, alpha, and beta bands during wakefulness, SWS, and REM sleep of wild-type littermate mice, orexin/Halo mice, and orexin/ataxin-3 mice during the light on period $(n=13)$. $\boldsymbol{D}$, Bar graph summarizes the firing frequency of serotonergic neurons in the DR during wakefulness, SWS, and REM sleep recorded from wild-type littermate mice $(n=9-22)$, orexin/Halo mice $(n=6-26)$, and orexin/ataxin-3 mice $(n=12-17)$. $\boldsymbol{E}$, Confirmation of an extracellular recording from neurons in the DR. The arrow shows PSB labeling (blue), indicating the location of the tip of the recording electrode (left). Scale bar, $500 \mu \mathrm{m}$. The right is a higher magnification of the rectangle in the left (right). Scale bar, $300 \mu \mathrm{m} . \boldsymbol{F}, \boldsymbol{G}$, Representative EEG/EMG recordings and firing frequency of DR neurons during orange light illumination in wild-type mice $(\boldsymbol{F})$ and orexin/Halo mice (G). $\boldsymbol{H}$, Power spectral analysis of EEG recorded from orexin/Halo mice $(n=12)$. The top graph shows power spectra of spontaneously occurring wakefulness, SWS, and REM sleep observed in orexin/Halo mice during the lights-on period ( $n=6-26)$. The bottom graph shows power spectra: Pre, 30 s before illumination; Post, 30 s after illumination; 0 - 30 s, the first half 30 sillumination; 30 - 60 s, the second half 30 sillumination in orexin/Halo mice during the lights on period $(n=6-26)$.I, The average EEG power densities in the delta, theta, alpha, and beta wave bands $(n=12)$. Average power significantly increased in the second half of light illumination in all four frequency bands. J, Bar graph summarizing the firing frequency of serotonergic DR neurons during orange light illumination of orexin/Halo mice ( $n=$ 12). $\boldsymbol{K}$, Bar graph summarizing integrated EMG levels. Integrated EMG levels were normalized to Pre, 30 s before illumination. Values are represented as means \pm SEM. ${ }^{*} p<0.05$.

Table 3. Episode duration of wakefulness, SWS, and REM sleep during light period of orexin/Halo transgenic mice and wild-type mice

\begin{tabular}{lll}
\hline & Wild-type mice & orexin/Halo mice \\
\hline Wakefulness (s) & $80.3 \pm 21.5$ & $69.6 \pm 14.2$ \\
SWS (s) & $81.6 \pm 10.4$ & $79.9 \pm 9.9$ \\
REM sleep (s) & $82.2 \pm 22.5$ & $76.0 \pm 12.6$ \\
\hline
\end{tabular}

Optogenetic activation of orexin neurons through channelrhodopsin-2, a blue light-activated nonselective cation channel, increased wakefulness and reduced SWS and REM sleep (Adamantidis et al., 2007; Carter et al., 2009). Here, orexin neuron inhibition promoted SWS, suggesting that activity of orexin neurons is critical to maintain arousal in the light period. In contrast, 
inhibition of orexin neurons failed to induce SWS in the dark period. Carter et al. (2009) reported similar results in that orexin neuron-induced arousal was diminished by sleep deprivation and at specific circadian phases. This diurnal difference in efficacy might be attributable differences in sleep pressure across the day. During the light period, homeostatic sleep pressure is relatively high. At this time of day, the silencing of orexin neurons decreased the activity of serotonergic DR neurons (and likely other monoaminergic neurons), which would create conditions that are permissive for the occurrence of SWS. Conversely, the presence of neither orexin nor orexin neurons are required for wakefulness to occur during the light period because both the orexin ligand (Chemelli et al., 1999; Mochizuki et al., 2004) and orexin cell knock-out (Hara et al., 2001) mice have nearly normal levels of sleep and wake during the light period. During the dark period, in contrast, homeostatic sleep pressure is relatively low and inhibition of orexin neurons at this time of day might be insufficient to induce SWS as a result of high activity of other wake-promoting systems. Alternatively, the Halo-induced current might not be great enough to completely block the activity of orexin neurons during the dark period. Because the orexin antagonist almorexant induces sleep during the dark period (BrisbareRoch et al., 2007), the latter alternative is more likely.

\section{Acute inhibition of orexin neurons decreased firing in DR neurons}

Serotonergic DR neurons show tonic firing during wakefulness, decreased firing during SWS, and complete silence during REM sleep (McGinty and Harper, 1976). Our extracellular recordings of DR neurons corroborate these conclusions. Serotonergic neurons are densely innervated by orexin neurons and are directly and indirectly activated by orexin (Nambu et al., 1999; Brown et al., 2001). Conversely, serotonergic neurons innervate and inhibit orexin neurons (Muraki et al., 2004). Here, acute silencing of orexin neurons induced a gradual decrease in the firing frequency in DR serotonergic neurons to the same level as observed in SWS. This suggests that the activity of serotonergic neurons is highly dependent on orexin neuronal activity. Whether a similar inhibition occurs in other orexin projection sites such as the LC and TMN remains to be determined, particularly because channelrhodopsin-mediated stimulation of orexin neurons activates these nuclei (Carter et al., 2009). Interestingly, rebound activation of orexin neurons occurred when Halo inhibition was terminated, and the firing rate of DR serotonergic neurons also increased at this time. This rebound excitation of orexin neurons might also activate neurons in other orexin projection sites as well. Collectively, this rebound excitation of orexin neurons and orexin projection sites may underlie the wakefulness induction that occurs just after cessation of orexin neuron photic inhibition.

We expected that the activity of serotonergic neurons in orexin/ataxin-3 mice would be reduced during wakefulness relative to wild-type mice. Surprisingly, however, serotonergic DR neurons in orexin/ataxin-3 mice showed no differences in firing frequency in any state compared with wild-type mice. Orexin/ ataxin-3 mice have normal serotonin levels in the forebrain (Mori et al., 2010). These results indicate that the activity of serotonergic DR neurons is normally highly influenced by orexin neuronal activity but, in the chronic absence of orexin input, compensation can occur.

\section{Perspective}

In narcoleptic humans, the most common initial symptom is EDS, which is subsequently followed by other symptoms of the narcoleptic tetrad (Okun et al., 2002; Morrish et al., 2004; Ohayon et al., 2005). Our results may be relevant to this symptom progression. Initial dysfunction of orexin neurons would result in decreased excitatory drive and reduced activity of arousalpromoting monoaminergic nuclei, thereby contributing to EDS. As the orexin neurons degenerate, the activity of monoaminergic neurons would likely become less dependent on orexin, perhaps as plastic reassembly of the neuronal circuit underlying sleep/ wakefulness control occurs or through a change of the membrane properties of the neurons involved. Although compensatory regulation of the DR neurons may occur in the chronic absence of orexin, it apparently does not mitigate the symptomatology in orexin/ataxin-3 mice nor, presumably, in narcoleptic humans. These factors might contribute to the progression from EDS during the initial phase of orexin neuron dysfunction to the subsequent symptomatology of narcolepsy, including cataplexy, when neurodegeneration occurs.

In summary, this study provides the first example of sleep induction via optogenetic silencing of a specific type of neuron, because the orexin/Halo transgenic mice enabled us to control the transition from wakefulness to SWS. Furthermore, the silencing of orexin neurons and transition to SWS was accompanied by a reduction in the firing rate in an efferent projection site of the orexin neurons, the DR, a brain region that has long been implicated in arousal state control.

Note added in proof. Recent work by Sasaki et al. (2011) also indicated importance of orexin neurons in the maintenance of arousal. They manipulated the activity of orexin neurons using a new method called the Designer Receptors Exclusively Activated by Designer Drugs approach (DREADD). Using this system, excitation of orexin neurons significantly increased the amount of time spent in wakefulness and decreased both REM and nonREM sleep times. Inhibition of orexin neurons decreased wakefulness time and increased non-REM sleep time.

\section{References}

Adamantidis AR, Zhang F, Aravanis AM, Deisseroth K, de Lecea L (2007) Neural substrates of awakening probed with optogenetic control of hypocretin neurons. Nature 450:420-424.

Arrenberg AB, Del Bene F, Baier H (2009) Optical control of zebrafish behavior with halorhodopsin. Proc Natl Acad Sci U S A 106:17968-17973.

Bayer L, Eggermann E, Serafin M, Saint-Mleux B, Machard D, Jones B, Mühlethaler M (2001) Orexins (hypocretins) directly excite tuberomammillary neurons. Eur J Neurosci 14:1571-1575.

Brisbare-Roch C, Dingemanse J, Koberstein R, Hoever P, Aissaoui H, Flores S, Mueller C, Nayler O, van Gerven J, de Haas SL, Hess P, Qiu C, Buchmann S, Scherz M, Weller T, Fischli W, Clozel M, Jenck F (2007) Promotion of sleep by targeting the orexin system in rats, dogs and humans. Nat Med 13:150-155.

Brown RE, Sergeeva O, Eriksson KS, Haas HL (2001) Orexin A excites serotonergic neurons in the dorsal raphe nucleus of the rat. Neuropharmacology 40:457-459.

Brown RE, Sergeeva OA, Eriksson KS, Haas HL (2002) Convergent excitation of dorsal raphe serotonin neurons by multiple arousal systems (orexin/hypocretin, histamine and noradrenaline). J Neurosci 22:8850-8859.

Carter ME, Adamantidis A, Ohtsu H, Deisseroth K, de Lecea L (2009) Sleep homeostasis modulates hypocretin-mediated sleep-to-wake transitions. J Neurosci 29:10939-10949.

Chemelli RM, Willie JT, Sinton CM, Elmquist JK, Scammell T, Lee C, Richardson JA, Williams SC, Xiong Y, Kisanuki Y, Fitch TE, Nakazato M, Hammer RE, Saper CB, Yanagisawa M (1999) Narcolepsy in orexin knockout mice: molecular genetics of sleep regulation. Cell 98:437-451. de Lecea L, Kilduff TS, Peyron C, Gao X, Foye PE, Danielson PE, Fukuhara 
C, Battenberg EL, Gautvik VT, Bartlett FS 2nd, Frankel WN, van den Pol AN, Bloom FE, Gautvik KM, Sutcliffe JG (1998) The hypocretins: hypothalamus-specific peptides with neuroexcitatory activity. Proc Natl Acad Sci U S A 95:322-327.

Hagan JJ, Leslie RA, Patel S, Evans ML, Wattam TA, Holmes S, Benham CD, Taylor SG, Routledge C, Hemmati P, Munton RP, Ashmeade TE, Shah AS, Hatcher JP, Hatcher PD, Jones DN, Smith MI, Piper DC, Hunter AJ, Porter RA, Upton N (1999) Orexin A activates locus coeruleus cell firing and increases arousal in the rat. Proc Natl Acad Sci U S A 96:10911-10916.

Han X, Boyden ES (2007) Multiple-color optical activation, silencing, and desynchronization of neural activity, with single-spike temporal resolution. PLoS One 2:e299.

Hara J, Beuckmann CT, Nambu T, Willie JT, Chemelli RM, Sinton CM, Sugiyama F, Yagami K, Goto K, Yanagisawa M, Sakurai T (2001) Genetic ablation of orexin neurons in mice results in narcolepsy, hypophagia, and obesity. Neuron 30:345-354.

Horvath TL, Peyron C, Diano S, Ivanov A, Aston-Jones G, Kilduff TS, van Den Pol AN (1999) Hypocretin (orexin) activation and synaptic innervation of the locus coeruleus noradrenergic system. J Comp Neurol 415:145-159.

Lee MG, Hassani OK, Jones BE (2005) Discharge of identified orexin/hypocretin neurons across the sleep-waking cycle. J Neurosci 25:6716-6720.

Lin L, Faraco J, Li R, Kadotani H, Rogers W, Lin X, Qiu X, de Jong PJ, Nishino S, Mignot E (1999) The sleep disorder canine narcolepsy is caused by a mutation in the hypocretin (orexin) receptor 2 gene. Cell 98:365-376.

McGinty DJ, Harper RM (1976) Dorsal raphe neurons: depression of firing during sleep in cats. Brain Res 101:569-575.

Mileykovskiy BY, Kiyashchenko LI, Siegel JM (2005) Behavioral correlates of activity in identified hypocretin/orexin neurons. Neuron 46:787-798.

Mochizuki T, Crocker A, McCormack S, Yanagisawa M, Sakurai T, Scammell TE (2004) Behavioral state instability in orexin knock-out mice. J Neurosci 24:6291-6300.

Mori T, Ito S, Kuwaki T, Yanagisawa M, Sakurai T, Sawaguchi T (2010) Monoaminergic neuronal changes in orexin deficient mice. Neuropharmacology 58:826-832.

Moriguchi T, Sakurai T, Takahashi S, Goto K, Yamamoto M (2002) The human prepro-orexin gene regulatory region that activates gene expression in the lateral region and represses it in the medial regions of the hypothalamus. J Biol Chem 277:16985-16992.

Morrish E, King MA, Smith IE, Shneerson JM (2004) Factors associated with a delay in the diagnosis of narcolepsy. Sleep Med 5:37-41.

Muraki Y, Yamanaka A, Tsujino N, Kilduff TS, Goto K, Sakurai T (2004) Serotonergic regulation of the orexin/hypocretin neurons through the 5-HT1A receptor. J Neurosci 24:7159-7166.

Nambu T, Sakurai T, Mizukami K, Hosoya Y, Yanagisawa M, Goto K (1999) Distribution of orexin neurons in the adult rat brain. Brain Res 827: 243-260.

Ohayon MM, Ferini-Strambi L, Plazzi G, Smirne S, Castronovo V (2005) How age influences the expression of narcolepsy. J Psychosom Res 59:399-405.

Okun ML, Lin L, Pelin Z, Hong S, Mignot E (2002) Clinical aspects of narcolepsy-cataplexy across ethnic groups. Sleep 25:27-35.

Peyron C, Tighe DK, van den Pol AN, de Lecea L, Heller HC, Sutcliffe JG, Kilduff TS (1998) Neurons containing hypocretin (orexin) project to multiple neuronal systems. J Neurosci 18:9996-10015.

Peyron C, Faraco J, Rogers W, Ripley B, Overeem S, Charnay Y, Nevsimalova S, Aldrich M, Reynolds D, Albin R, Li R, Hungs M, Pedrazzoli M, Padigaru M, Kucherlapati M, Fan J, Maki R, Lammers GJ, Bouras C, Kucherlapati R, Nishino S, Mignot E (2000) A mutation in a case of early onset narcolepsy and a generalized absence of hypocretin peptides in human narcoleptic brains. Nat Med 6:991-997.

Piper DC, Upton N, Smith MI, Hunter AJ (2000) The novel brain neuropeptide, orexin-A, modulates the sleep-wake cycle of rats. Eur J Neurosci 12:726-730.

Sakurai T (2007) The neural circuit of orexin (hypocretin): maintaining sleep and wakefulness. Nat Rev Neurosci 8:171-181.

Sakurai T, Amemiya A, Ishii M, Matsuzaki I, Chemelli RM, Tanaka H, Williams SC, Richardson JA, Kozlowski GP, Wilson S, Arch JR, Buckingham RE, Haynes AC, Carr SA, Annan RS, McNulty DE, Liu WS, Terrett JA, Elshourbagy NA, Bergsma DJ, Yanagisawa M (1998) Orexins and orexin receptors: a family of hypothalamic neuropeptides and G proteincoupled receptors that regulate feeding behavior. Cell 92:573-585.

Sakurai T, Moriguchi T, Furuya K, Kajiwara N, Nakamura T, Yanagisawa M, Goto K (1999) Structure and function of human prepro-orexin gene. J Biol Chem 274:17771-17776.

Sakurai T, Nagata R, Yamanaka A, Kawamura H, Tsujino N, Muraki Y, Kageyama H, Kunita S, Takahashi S, Goto K, Koyama Y, Shioda S, Yanagisawa M (2005) Input of orexin/hypocretin neurons revealed by a genetically encoded tracer in mice. Neuron 46:297-308.

Sasaki K, Suzuki M, Mieda M, Tsujino N, Roth B, Sakurai T (2011) Pharmacogenetic modulation of orexin neurons alters sleep/wakefulness states in mice. PLoS One 6:e20360.

Takahashi K, Wang QP, Guan JL, Kayama Y, Shioda S, Koyama Y (2005) State-dependent effects of orexins on the serotonergic dorsal raphe neurons in the rat. Regul Pept 126:43-47.

Takahashi K, Lin JS, Sakai K (2008) Neuronal activity of orexin and nonorexin waking-active neurons during wake-sleep states in the mouse. Neuroscience 153:860-870.

Thannickal TC, Moore RY, Nienhuis R, Ramanathan L, Gulyani S, Aldrich M, Cornford M, Siegel JM (2000) Reduced number of hypocretin neurons in human narcolepsy. Neuron 27:469-474.

Tobler I, Deboer T, Fischer M (1997) Sleep and sleep regulation in normal and prion protein-deficient mice. J Neurosci 17:1869-1879.

Tsujino N, Yamanaka A, Ichiki K, Muraki Y, KilduffTS, Yagami K, Takahashi S, Goto K, Sakurai T (2005) Cholecystokinin activates orexin/hypocretin neurons through the cholecystokinin A receptor. J Neurosci 25: $7459-7469$

Willie JT, Chemelli RM, Sinton CM, Tokita S, Williams SC, Kisanuki YY, Marcus JN, Lee C, Elmquist JK, Kohlmeier KA, Leonard CS, Richardson JA, Hammer RE, Yanagisawa M (2003) Distinct narcolepsy syndromes in Orexin receptor-2 and Orexin null mice: molecular genetic dissection of Non-REM and REM sleep regulatory processes. Neuron 38:715-730.

Yamanaka A, Tsujino N, Funahashi H, Honda K, Guan JL, Wang QP, Tominaga M, Goto K, Shioda S, Sakurai T (2002) Orexins activate histaminergic neurons via the orexin 2 receptor. Biochem Biophys Res Commun 290:1237-1245.

Yamanaka A, Muraki Y, Tsujino N, Goto K, Sakurai T (2003a) Regulation of orexin neurons by the monoaminergic and cholinergic systems. Biochem Biophys Res Commun 303:120-129.

Yamanaka A, Beuckmann CT, Willie JT, Hara J, Tsujino N, Mieda M, Tominaga M, Yagami K, Sugiyama F, Goto K, Yanagisawa M, Sakurai T (2003b) Hypothalamic orexin neurons regulate arousal according to energy balance in mice. Neuron 38:701-713.

Zhang F, Wang LP, Brauner M, Liewald JF, Kay K, Watzke N, Wood PG, Bamberg E, Nagel G, Gottschalk A, Deisseroth K (2007) Multimodal fast optical interrogation of neural circuitry. Nature 446:633-639.

Zhao S, Cunha C, Zhang F, Liu Q, Gloss B, Deisseroth K, Augustine GJ, Feng G (2008) Improved expression of halorhodopsin for light-induced silencing of neuronal activity. Brain Cell Biol 36:141-154. 